\title{
Effect of Implementing Breastfeeding Promotion Program in Neonatal Intensive Care Unit on Newborn Weight and Breastfeeding Practices
}

\author{
Abeer El Sakka a, , Mohamed Sami El Shimia, Sara Hamed Ibrahium
}

\begin{abstract}
Background: Mothers of very low birth weight (VLBW) infants have challenges breastfeeding their infants. Even if not intending to breastfeed, they may be encouraged to do so for short-term to protect their infants. Yet, they need consultation to assist initiation, and maintenance of breastfeeding. The objective of this study was to determine the effect of implementation of Breastfeeding Promotion Program in the Neonatal Intensive Care Unit (NICU) on breastfeeding practices and newborn weight.
\end{abstract}

Methods: A Breastfeeding Educational Promotion Initiative Program was started in the NICU. Our targets were health care professionals, social workers and staff in the NICU as well as mothers of VLBW infants admitted to the NICU. Forty-six VLBW infants were included in the study. We compared the newborn weight and breastfeeding practices such as number of mothers' visits, and breastfeeding rate at time of discharge from the NICU between two groups. Group $\mathrm{A}, \mathrm{n}=23$, pre-intervention and group $\mathrm{B}, \mathrm{n}=23$, post-intervention.

Results: Infants weight at discharge and percentage increase in weight gain were more in group B which showed significant difference $(P=0.02)$ and $(P<0.01)$ respectively. Expressed breast milk per day was more in group $\mathrm{B}$ with significant difference $(\mathrm{P}<0.005)$. The number of mothers' visit and the percentage of breastfeeding at time of discharge were more in group B with highly statistically significant difference $(\mathrm{P}=0.001$ and 0.0001 respectively).

Conclusion: Implementation of a Breastfeeding Educational Promotion Program in the NICU improved newborn weight gain and breastfeeding practices.

Keywords: Breastfeeding; Newborn; Promotion; Education

\footnotetext{
Manuscript accepted for publication June 27, 2014

${ }^{a}$ Ain Shams University, Faculty of Medicine, Neonatal Intensive Care Unit, Cairo, Egypt

${ }^{\mathrm{b}}$ Corresponding Author: Abeer El Sakka, 38 Abbassia, Cairo 11566,

Egypt. Email: drasakka@ymail.com
}

doi: http://dx.doi.org/10.14740/ijcp159w

\section{Introduction}

Breastfeeding is recognized as the best source of nutrition for all infants, and the World Health Organization (WHO) recommends exclusive breastfeeding until 6 months of age [1]. The AAP recommends those 6 months should be followed by continued breastfeeding after the addition of complementary foods for at least 1 year or until mutually desired by mother and child [2].

The American Academy of Pediatrics issued a statement in February 2005 which stated that breastfeeding or human milk feedings are recommended for all healthy premature and high-risk infants for whom breastfeeding is not specifically contraindicated. It further stated that health care professionals should provide complete, current and accurate information to parents on the benefits and techniques involved with breastfeeding [3].

Literature suggests that there is lack of health care professionals who are trained in lactation and breastfeeding with premature babies, and that many health care professionals have incorrect knowledge and negative beliefs about lactation $[4,5]$. Studies have identified that education and training can affect attitudes and knowledge about breastfeeding [6].

In almost all countries with reliable data, preterm birth rates are increasing. Globally, prematurity is the leading cause of newborn deaths and now the second leading cause of death after pneumonia in children under the age of 5. Inequalities in survival rates around the world are evident. In low-income settings, half of the babies born at 32 weeks die due to a lack of feasible, cost-effective care such as warmth, breastfeeding support, basic care for infections and breathing difficulties. In high-income countries, almost all of these babies survive [7].

Breastfeeding promotion in the NICU faces a unique set of challenges. Because many of the infants are premature, oral motor skills are often poorly developed and these infants may display an inability to latch and suck [8]. This means that mothers must often use manual or electronic breast pumps to express milk, which is then fed to the infant by gavage or oral feeds [9].

The aim of the study was to determine the growth out- 
Table 1. Maternal Demographic Data in the Two Groups

\begin{tabular}{|c|c|c|c|c|c|c|c|c|c|}
\hline & & \multicolumn{2}{|c|}{ Group A } & \multicolumn{2}{|c|}{ Group B } & \multicolumn{2}{|c|}{ Total } & \multicolumn{2}{|c|}{ Chi-square } \\
\hline & & $\mathbf{N}$ & $\%$ & $\mathbf{N}$ & $\%$ & $\mathbf{N}$ & $\%$ & $\mathbf{X}^{2}$ & P-value \\
\hline \multirow[t]{4}{*}{ Parity } & 0 & 10 & 47.62 & 11 & 52.38 & 21 & 45.65 & 1.099 & 0.777 \\
\hline & 1 & 4 & 57.14 & 3 & 42.86 & 7 & 15.22 & & \\
\hline & 2 & 6 & 60.00 & 4 & 40.00 & 10 & 21.74 & & \\
\hline & 3 & 3 & 37.50 & 5 & 62.50 & 8 & 17.39 & & \\
\hline \multirow{6}{*}{$\begin{array}{l}\text { Risk factors for } \\
\text { preterm birth }\end{array}$} & PPROM & 7 & 53.85 & 6 & 46.15 & 13 & 28.26 & 10.676 & 0.058 \\
\hline & SPET & 8 & 53.33 & 7 & 46.67 & 15 & 32.61 & & \\
\hline & IUGR & 0 & 0.00 & 3 & 100.00 & 3 & 6.52 & & \\
\hline & Twines & 7 & 63.64 & 4 & 36.36 & 11 & 23.91 & & \\
\hline & Chronic ITP & 1 & 100.00 & 0 & 0.00 & 1 & 2.17 & & \\
\hline & PPROM & 0 & 0.00 & 3 & 100.00 & 3 & 6.52 & & \\
\hline \multirow[t]{2}{*}{ MOD } & LSCS & 17 & 43.59 & 22 & 56.41 & 39 & 84.78 & 4.605 & 0.032 \\
\hline & SVD & 6 & 85.71 & 1 & 14.29 & 7 & 2 & & \\
\hline
\end{tabular}

PPROM: preterm pre-mature rupture of membrane; SPET: severe pre-eclamptic toxemia; IUGR: intra-uterine growth retardation; ITP: idiopathic thrombocytopenic purpura; MOD: mode of delivery; LSCS: lower segment caesarian section; SVD: spontaneous vaginal delivery.

comes and breastfeeding rate before and after implementation of Educational Promotional Breastfeeding Program at the Neonatal Intensive Care Unit (NICU) at Ain Shmas University Women's Hospital in Cairo, Egypt.

\section{Materials and Methods}

This is a retrospective observational study, which included 46 very low birth weight (VLBW) neonates with birth weight less than $1,800 \mathrm{~g}$. Newborns were not eligible for inclusion in the study if their birth weight was $>1,800$, or had congenital anomalies, or their mothers were not willing to breastfeed, or had infections as HIV, herpetic breast lesion, active tuberculosis, or were receiving drugs L5 category [10, 11].

This study was conducted at Ain Shams University Women's Hospital from October 2012 till December 2013. We used the medical records to access data of newborns one year before inclusion of this program (group $A, n=23$ ) and compared it with the data one year after (group $\mathrm{B}, \mathrm{n}=$
23). Maternal data included parity, risk factors for preterm birth and maternal illness during pregnancy, medical complications during or after labor. Newborns data included gestational age mode of delivery, birth weight at admission, length of hospital stay, rate of weight gain, amount of mother's breast milk fed per day and breastfeeding at time of NICU discharge.

We implemented a Breastfeeding Educational Promotion Program for 4 weeks. We included health care providers involved in newborn care in the NICU as neonatologists, nurses and rehabilitation therapists. Social workers and other NICU staff, as well as mothers of VLBW infants were our targets in the program. Our tools varied between lectures, videos, case studies, demonstrations and reference textbooks.

The topics covered physiology of lactation, benefits of breastfeeding, barriers to breastfeeding, breast milk expression and storage, usage of breast pumps, pre-feeding interventions as skin to skin contact, non-nutritive suckling and assessment of breastfeeding. After 4 weeks, the program was implemented in the NICU.

The program contributed the following for mothers of 
Table 2. Newborn Demographic Data in Both Groups

\begin{tabular}{|c|c|c|c|c|}
\hline & & Group A & Group B & P-value \\
\hline \multirow[t]{2}{*}{ GA, mean (SD) (wk) } & Range & $23.00-35.00$ & $28.00-39.00$ & 0.30 \\
\hline & Mean \pm SD & $30.39 \pm 2.35$ & $32.04 \pm 2.65$ & \\
\hline \multirow[t]{2}{*}{ Ballard score (wk) } & Range & $30.00-35.00$ & $30.00-35.00$ & 0.18 \\
\hline & Mean \pm SD & $32.04 \pm 1.52$ & $32.65 \pm 1.53$ & \\
\hline \multirow[t]{2}{*}{ Sex } & Female & $14(60.87 \%)$ & $12(52.17 \%)$ & 0.552 \\
\hline & Male & $9(39.13 \%)$ & $11(47.83 \%)$ & \\
\hline
\end{tabular}

GA: gestational age; wk: week.

VLBW newborns: how to express breast milk, chose the proper breast pump, use containers to store her milk and transport the milk to the NICU. Lactation services education consisted of one-to-one and group skills sessions, and telephone consultations and advices for mothers.

We provided the mothers with educational pamphlets showing breastfeeding positions, proper latching techniques and instructions for expression and storage of breast milk. These were written in fifth grade level with many illustrations to facilitate learning for illiterate mothers.

We adopted the guiding principles for the expansion of the Baby-Friendly Hospital Initiative (BFHI) for NICUs
[12], which consist of 1) focusing the staff attitude toward the individual mothers with stressing on psychological support; 2) providing family-centered care and support of the natural parental role; 3 ) ensuring continuity of care that is pre-, peri-, post-natal and post-discharge care.

We added a breastfeeding follow-up plan to the newborn's medical chart. These documented specific key points that predicted breastfeeding behavior such as number of mother's visits for direct breastfeeding, amount of expressed milk/day and breastfeeding at time of discharge from the NICU, weight at admission and discharge. We allowed flexible times for the mother to visit and breastfeed her newborn.

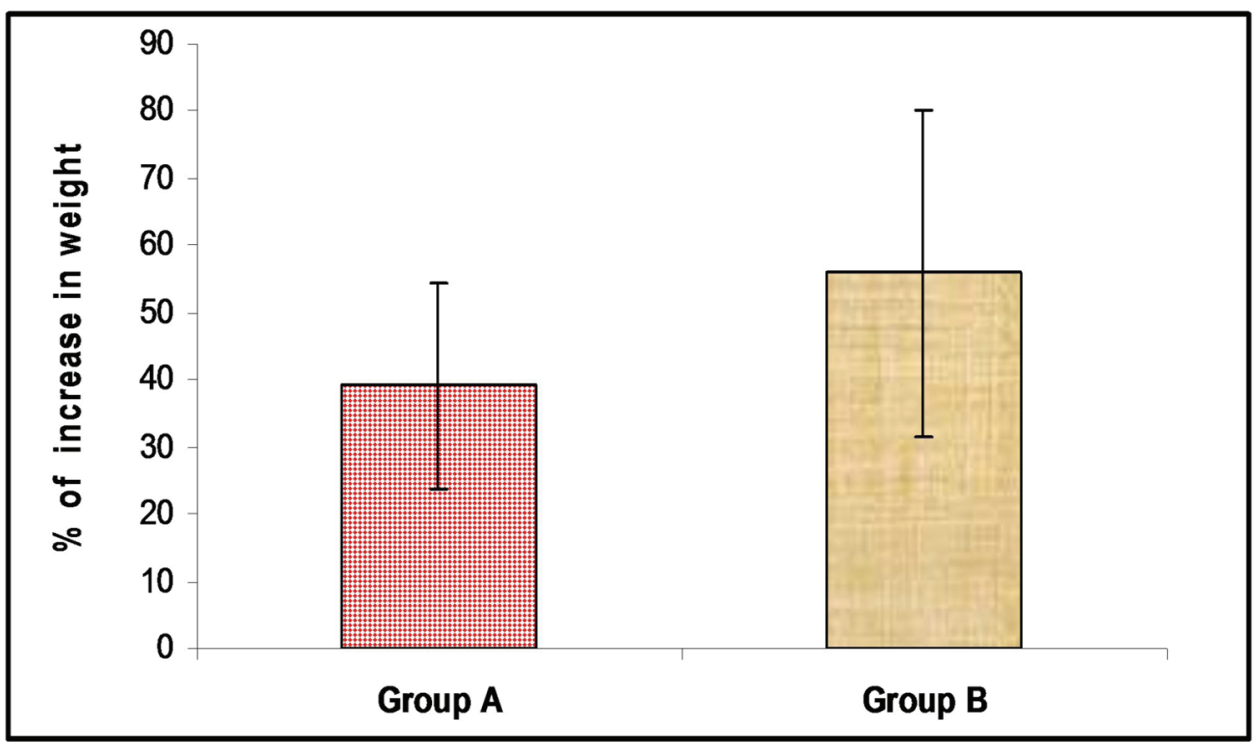

Figure 1. Comparison between the percentage of the change in weight in the two groups during NICU stay, P< 0.01 . $P^{*}<0.05$ is significant, $P^{* *}<0.01$ is highly significant and $P<0.001$ is very highly significant. 
Table 3. Comparison Between Both Groups As Regards Newborns Weight and Breastfeeding Practices

\begin{tabular}{llll}
\hline & Group A & Group B & \\
& & & \\
& Mean \pm SD & Mean \pm SD & \\
& & & \\
& $1,260 \pm 130$ & $1,240 \pm 190$ & 0.71 \\
Weight at admission/g & $1,760 \pm 110$ & $1,850 \pm 150$ & 0.02 \\
Weight at discharge/g & $39.08 \pm 15.43$ & $55.94 \pm 24.27$ & $<0.01$ \\
Percent increase in infant weight & $6.05 \pm 1.62$ & $<0.001$ \\
Number of mother visits/day & $1.3 \pm 0.62$ & $111.63 \pm 28.64$ & $<0.01$ \\
Breast-milk volume/day & $40.36 \pm 28.9$ & 100 & $<0.0001$ \\
$\begin{array}{l}\text { Percent of breastfeeding at time } \\
\text { of discharge }\end{array}$ & 43.48 & & \\
\hline
\end{tabular}

\section{Statistical methods}

Statistical significance was defined as P-value $<0.05$. Analysis was performed using SPSS statistical software package version 20 .

\section{Results}

There was no significant difference between the two groups $(\mathrm{P}>0.05)$ except for mode of delivery with more vaginal deliveries in group A (Table 1,2). There was no difference between the two groups as regards weight at admission $(\mathrm{P}>$ 0.05 ). While the weight at discharge and percentage increase in weight gain (Fig. 1) were more in group B with significant difference $(\mathrm{P}<0.01$ and $\mathrm{P}<0.01$ respectively). Breast milk volume per day was more in group $\mathrm{B}$ with significant difference $(\mathrm{P}<0.005)$ (Table 3$)$. The number of mothers' visits for direct breastfeeding, and the percentage of breastfeeding at time of discharge (Fig. 2) were more in group B with statistic significance $(\mathrm{P}<0.001$ and $<0.0001$ respectively $)$.

\section{Discussion}

The best choice for feeding preterm infants is breastfeeding or expressed mothers' milk. There is strong and consistent evidence that feeding preterm infants of any gestational age by their own mothers' milk are associated with a lower incidence of infections and necrotizing enterocolitis (NEC) [13]. Breast milk increased immunological protection, improved gastrointestinal function and enhanced cognitive development [3] compared to feeding with formula. The potent benefits of human milk are such that all preterm infants should receive human milk [14].

Despite these benefits, the rates of breastfeeding are much lower among preterm infants. Compared to term infants, preterm infants have an immature and disorganized sucking pattern that delays the attainment of exclusive breastfeeding. However, research has shown that infants can root, efficiently grasp the areola, and perform short sucking bursts as early as 29 weeks and achieve nutritional breastfeeding from 31 st week [15].

In our study the maternal demographic data in the two groups showed no statistical significant difference in preand post-intervention groups as regards maternal parity, premature rupture of membranes, intra-uterine growth retardation (IUGR) and multiple pregnancy $(\mathrm{P}>0.05)$.

There was high incidence of lower cesarean section (LSCS) in both groups with more LSCS in group A, $\mathrm{P}<0.03$. The infants' demographic data such as gestational age, Ballard score and gender showed no statistical significant difference between the two groups $(\mathrm{P}>0.05)$. This is in agreement with Nahid et al [16] who found that their two groups were similar regarding gestational age, birth weight and gender $(\mathrm{P}$ $=0.05$ ).

Karel et al [17] showed that the demographic and treatment characteristics that were collected from the infants enrolled in their study, including gestational age, birth weight, small for gestational age, singleton status, Apgar score at 1 $\min$ and $5 \mathrm{~min}$, and corrected gestational age showed no significant difference $(\mathrm{P}>0.05)$.

Jenny et al [18] found that there were no significant differences between their two groups as regards gender $(\mathrm{P}=$ $1.00)$ and gestational age $(\mathrm{P}=0.24)$.

In this study, there was no significant difference between the two groups in birth weight $(\mathrm{P}=0.71)$. This is in agreement with Nahid et al [16] who found that there was no sig- 


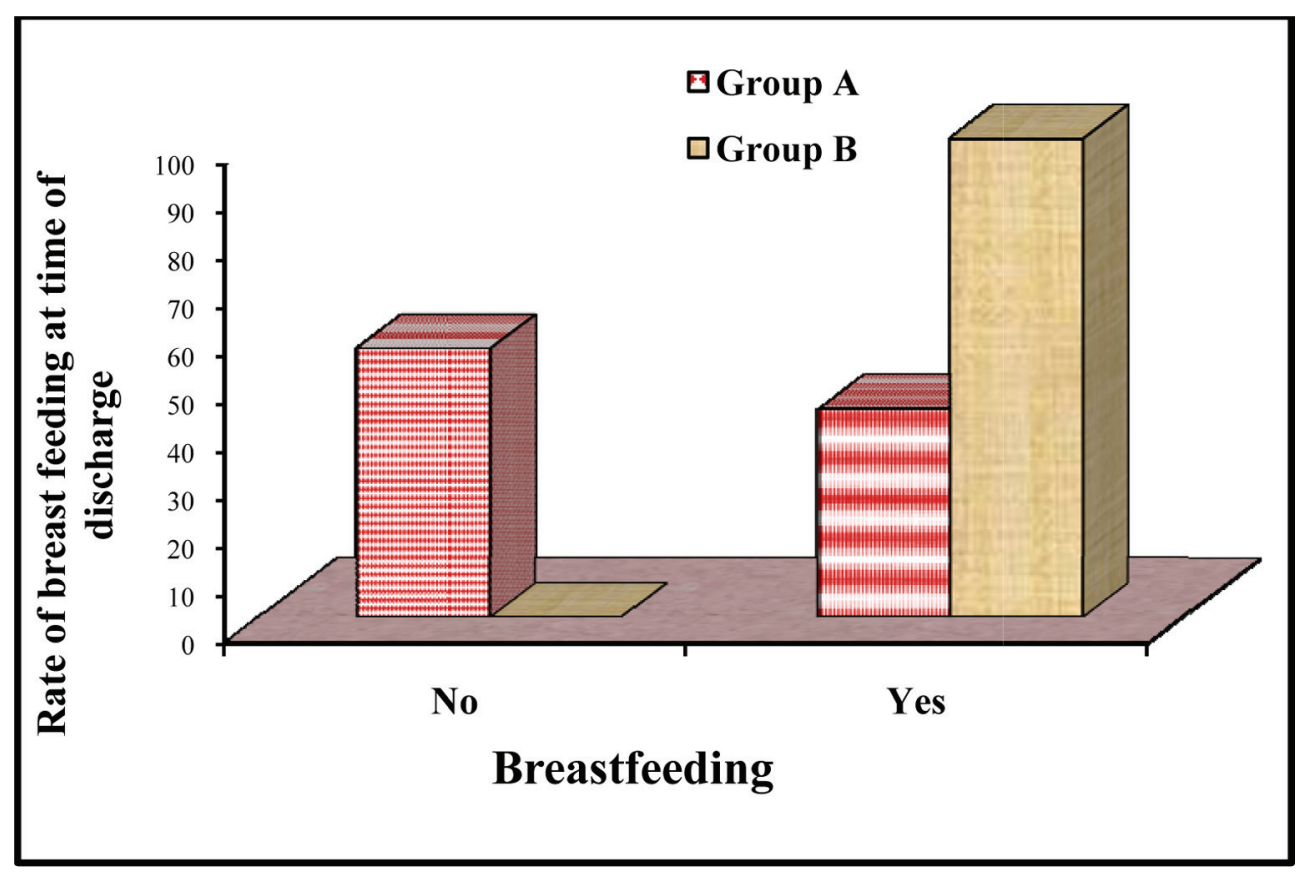

Figure 2. Comparison between rate of breastfeeding at time of discharge between the two groups, $P<0.0001$.

nificant difference in weight at admission in the intervention and control groups $(\mathrm{P}=0.15)$. Also Jenny et al [18] found no significant difference in weight at admission to the NICU (P $=0.62$ ).

But comparing the percentage of change in pre-intervention and post-intervention groups, there was significant difference with more weight gain in group $\mathrm{B}(\mathrm{P}=0.01)$. This is in agreement with Karel et al [17] who found that the rate of change in weight gain was significantly higher in Family Integrated Care infants compared with control infants $(\mathrm{P}<$ 0.05). Also Pineda [9] found that there was a significant increase in weight of infants after education and intervention $(\mathrm{P}=0.025)$.

Our study showed that the length of hospital stay was shorter in group B, and this difference was not statistically significant. This result agrees with Pineda [9] and Jenny et al [18] who found that there was no significant difference between the two groups in proportion of hospital stay. The number of mothers' visits for direct breastfeeding per day was highly significant between both groups with more visits in group $\mathrm{B}(\mathrm{P}=0.001)$. There was statistical significant difference in the rate of breastfeeding at discharge in the postintervention group B $(100 \%)$ in comparison with pre-intervention group A $(43.48 \%)(\mathrm{P}=0.0001)$. This is in agreement with Dall'Oglio et al [19] where they found that implementation of a Breastfeeding Promotion Program in the NICU had marked positive effect on exclusive breastfeeding rate early after discharge $(\mathrm{P}=0.001)$.

Also Pineda et al [20] found that the post-intervention group demonstrated significant improvement in rates of breastfeeding in the NICU compared with the pre-intervention group. General positive trends in breast milk feeding initiation (up 11\%) and breast milk feeding at discharge (up $5 \%$ ) were observed, but these failed to reach significance. Taylor et al [8] found that motivated staff, educational support and clear guidelines are essential to support implementation of the BFHI in NICUs. Karel et al [17] demonstrated that there were significant increase in the incidence of breastfeeding at discharge $(82.15 \%$ versus $45.5 \%, \mathrm{P}<0.05)$. Furthermore, Mei-Chiao et al [21] showed that breastfeeding instructions to mothers and their families by the nursing staff improved the breastfeeding rate for premature infants where it increased from $23.3 \%$ to $67.5 \%$.

This study showed that there was a highly significant difference in breast milk volume/day with greater volume in group $\mathrm{B}(\mathrm{P}=0.001)$. Similarly to what we observed, Paula et al [22] found that about $98 \%$ of mothers provided milk for their infants in the NICU, and the average daily amount of human milk received during the NICU hospitalization by VLBW infants exceeded $60 \mathrm{~mL} / \mathrm{kg} /$ day.

\section{Conclusion}

Application of Breastfeeding Educational Program in the NICU translates the knowledge about the benefits of breastfeeding into support of health care providers to mothers of preterm infants. This was reflected on better newborns weight and breastfeeding rate during and at the time of dis- 
charge from the NICU.

\section{Financial Support}

Authors' personal finances funded this research.

\section{Conflict of Interest}

The authors have reported no conflict of interest.

\section{Ethical Approval}

Ethical Committee of Ain Shams Medical School Pediatric Department approved this research.

\section{References}

1. Charlotte H, Stephanie G. Faculty Reviewer: Dr. Cynthia Kenyon, BSc MD FRCPC. The University of Western Ontario Medical Journal. 2012;81(1).

2. Schanler RJ, Frebs NF, Mass SB, Josef G. Breastfeeding handbook for Physicians, 2nd edition. The American Academy of Obstetricians and Gynecologists and The American Academy of Pediatrics. The American Academy of Pediatrics, 2014.

3. Gartner LM, Morton J, Lawrence RA, Naylor AJ, O'Hare D, Schanler RJ, Eidelman AI, et al. Breastfeeding and the use of human milk. Pediatrics. 2005;115(2):496-506.

4. Berens PD. Prenatal, intrapartum, and postpartum support of the lactating mother. Pediatr Clin North Am. 2001;48(2):365-375.

5. Spicer K. What every nurse needs to know about breast pumping: instructing and supporting mothers of premature infants in the NICU. Neonatal Netw. 2001;20(4):3541.

6. Swanson V, Power KG. Initiation and continuation of breastfeeding: theory of planned behaviour. J Adv Nurs. 2005;50(3):272-282.

7. Blencowe H, Cousens S, Oestergaard MZ, Chou D, Moller AB, Narwal R, Adler A, et al. National, regional, and worldwide estimates of preterm birth rates in the year 2010 with time trends since 1990 for selected countries: a systematic analysis and implications. Lancet. 2012;379(9832):2162-2172.

8. Taylor C, Gribble K, Sheehan A, Schmied V, Dykes F. Staff perceptions and experiences of implementing the Baby Friendly Initiative in neonatal intensive care units in Australia. J Obstet Gynecol Neonatal Nurs. 2011;40(1):25-34.
9. Pineda RG. Predictors of breastfeeding and breastmilk feeding among very low birth weight infants. Breastfeed Med. 2011;6(1):15-19.

10. Hale TW. Medications and Mother's Milk. 15th edition. Hale Publishing, 2012.

11. Sachs HC, Committee On D. The transfer of drugs and therapeutics into human breast milk: an update on selected topics. Pediatrics. 2013;132(3):e796-809.

12. Kerstin HN, Anna PH, Mette NH, Elisabeth K, Annem LF, Ragnhild M, Aino E, Leena H, Katja K, Laura NH. Expansion of the Ten Steps to Successful Breastfeeding into Neonatal Intensive Care: Expert Group Recommendations for Three Guiding Principles. 2012;28:289-296.

13. Edmond K, Bahl R. Optimal Feeding of Low-birthweight Infants. Technical Review. Geneva: World Health Organization; 2006.

14. Isaacs EB, Fischl BR, Quinn BT, Chong WK, Gadian DG, Lucas A. Impact of breast milk on intelligence quotient, brain size, and white matter development. Pediatr Res. 2010;67(4):357-362.

15. Nyqvist KH. Early attainment of breastfeeding competence in very preterm infants. Acta Paediatr. 2008;97(6):776-781.

16. Nahid D, Sousan V, Behzad J, Mohammad BH. The Effect of an Educational and Supportive Relactation Program on Weight Gain of Preterm Infants. Journal of Caring Sciences. 2013;2;(2):97-103.

17. O’Brien K, Bracht M, Macdonell K, McBride T, Robson K, O'Leary L, Christie K, et al. A pilot cohort analytic study of Family Integrated Care in a Canadian neonatal intensive care unit. BMC Pregnancy Childbirth. 2013;13(Suppl 1):S12.

18. Ericson J, Eriksson M, Hellstrom-Westas L, Hagberg L, Hoddinott $\mathrm{P}$, Flacking R. The effectiveness of proactive telephone support provided to breastfeeding mothers of preterm infants: study protocol for a randomized controlled trial. BMC Pediatr. 2013;13:73.

19. Dall'Oglio I, Salvatori G, Bonci E, Nantini B, D'Agostino G, Dotta A. Breastfeeding promotion in neonatal intensive care unit: impact of a new program toward a BFHI for high-risk infants. Acta Paediatr. 2007;96(11):16261631.

20. Pineda RG, Foss J, Richards L, Pane CA. Breastfeeding changes for VLBW infants in the NICU following staff education. Neonatal Netw. 2009;28(5):311-319.

21. Su MC, Tsai CF, Su TP, Hsu HH, Yeh SH. A Program to Improve Exclusive Breastfeeding of Premature Infants in a Neonatal Intensive Care Unit. Tzu Chi Nursing Journal. 2012;2(11):70-81.

22. Paula PM, Aloka LP, Harold R. Bigger, Beverly Rossman, Janet L. Engstrom. Supporting Breastfeeding in the Neonatal Intensive Care Unit Rush Mother's Milk Club as a Case Study of Evidence-Based Care. Pediatr Clin N Am. 2013;(60):209-226. 